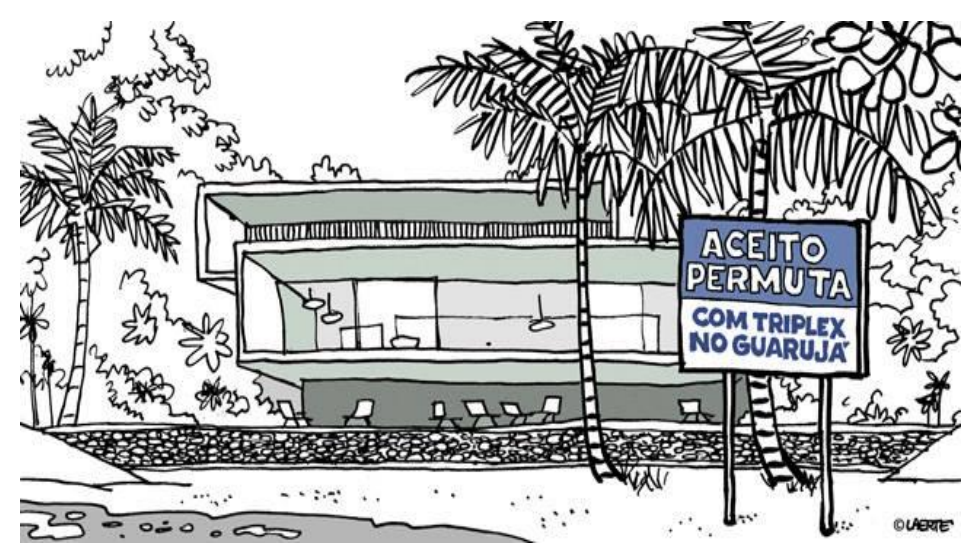

\title{
O tríplex: a imagem como operadora de memória discursiva em charges
}

The triplex: the image as a discursive memory operator in charges

Cristiane Renata da Silva Cavalcanti ${ }^{1}$ Nadia Pereira Gonçalves de Azevedo ${ }^{2}$

\section{Resumo:}

Este trabalho analisará, no discurso da charge, o papel da memória discursiva, enquanto efeito de sentido. Tem como ponto de partida a noção de memória discursiva, conforme os pilares da Análise do Discurso de Linha Francesa, (AD), fundada por Michel Pêcheux. Propomos a ideia de que a imagem é uma operadora, arte da memória social. Tal afirmação partiu da hipótese de que, em charges, há um relacionamento inerente entre a imagem e a memória, ou seja, há uma relação de sentido, através da memória social presente no interdiscurso. Para tanto, tomamos como objeto de análise três charges, veiculadas em jornais impresso e online. $\mathrm{O}$ trabalho pressupõe a perene incompletude dos fatos da linguagem, compreendendo que o dizer é sempre ponto de deriva para outros sentidos.

Palavras-chave: charge; interdiscurso ou memória discursiva; imagem: operadora de memória.

\section{Abstract:}

This work will analyze, in the discourse of charges, the role of discursive memory, as an effect of meaning. Its starting point is the notion of discursive memory, according to the pillars of the Analysis of the French Line Discourse (AD), founded by Michel Pêcheux. We propose the idea that the image is an operator, an art of social memory. This assumption was based on the hypothesis that in charges there is an inherent relationship between image and memory, that is, there is a relation of meaning through the social memory present in the interdiscourse. For that, we take as object of analysis three charges, published in print and online newspapers. The work presupposes the perennial incompleteness of the facts of the language, understanding that the saying is always point of drift towards other senses.

Keywords: charge; Interdiscourse or discursive memory; Image: memory operator.

\footnotetext{
${ }^{1}$ Doutoranda pelo Programa de Pós-graduação em Ciências da Linguagem (PPGCL) da Universidade Católica de Pernambuco. E-mail: reyelcris0862@gmail.com. Orcid: https://orcid.org/0000-0001-69844218

2 Professora adjunto III da Universidade Católica de Pernambuco, atuando na Graduação em Fonoaudiologia e como professora e pesquisadora no Programa de Pós-graduação stricto sensu em Ciências da Linguagem. E-mail: nadiaazevedo@gmail.com. Orcid: https://orcid.org/0000-0001-64252846
} 


\section{Introdução}

O presente trabalho faz uma análise discursiva de três charges, situando-as enquanto um gênero, levando em consideração a importância da imagem como operadora do papel da memória, sustentada na noção de interdiscurso que Pêcheux define como memória discursiva.

$\mathrm{Na}$ primeira parte do trabalho, procuraremos delinear o funcionamento discursivo do tipo de texto charge, trabalhando com o conceito de interdiscurso ou memória discursiva, em sua articulação com a história e a memória social, destacando a presença desse entrelaçamento. Posteriormente, procuraremos ampliar as reflexões da $\mathrm{AD}$ a respeito da imagem, como operadora da memória, que subsidiarão as análises; e por fim faremos a análise de três charges coletadas em jornais impresso e online.

Assim, analisaremos os discursos das charges, refletindo a partir de dois lugares importantes para a Análise do Discurso de Linha Francesa: a memória discursiva e, a imagem como operadora de memória.

Ao longo do trabalho, demonstraremos como a memória discursiva afeta a discursividade das charges analisadas, filiando-se à memória social e resinificando já ditos. A charge, como discurso, retoma, através da imagem, o acontecimento, a memória discursiva.

\section{A Charge}

O gênero charge vem do francês Charger e significa carregar, exagerar, segundo Rabaça \& Barbosa (1995). É uma cena pictórica de caráter caricatural, que caracteriza um fato específico, um acontecimento, situação ou personagem, em geral, de caráter político ou informação de domínio público. A escolha da análise deste gênero foi intencional, pois a charge sempre faz uma crítica a um determinado fato social ou político, com muitos ou poucos traços (verbal e não-verbal). Por meio dela, o chargista consegue dizer muito. Ela não somente informa, como também emite uma opinião e é carregada de interdiscursividade, um dos objetos do nosso estudo.

Esse trabalho tem sua importância, pois o gênero charge emite críticas e opiniões que podem iniciar uma reflexão e um posterior debate sobre um acontecimento importante na sociedade. Outra vantagem é que a análise das relações discursivas, por 
meio da charge, emite críticas humorísticas de determinados fatos específicos, geralmente discursos de natureza social e política que também é objetivo da pesquisa.

Sabemos também que tal gênero possui marcas verbais e não- verbais e essa relação entre discurso/imagem mostra, através das temáticas que abordam, como os sujeitos constroem suas identidades a partir dos personagens caricatos e de suas interações discursivas. Então, atravessada pela historicidade constitutiva do discurso, a charge envolve efeitos de sentido que não decorrem exclusivamente daquilo que se vê, ouve ou lê, mas que derivam de dizeres outros, deslocados e ressignificados no fio interdiscursivo, presentificando fatos e discursos que se deram em outros contextos históricos e que produzem sentidos que vão além da literalidade do dizer.

O estudo será pautado na teoria discursiva com base na Análise do Discurso de linha francesa, doravante, $\mathrm{AD}$, na concepção de discurso visto como acontecimento que se ancora num dado contexto e que serve de base para construir processos de identificação e de significação, pois estes implicam no Sujeito, constituído na/pela linguagem. Levamos em consideração, no texto, que a ideologia é materializada no discurso e, nesse sentido, indissociável do político, que trabalharemos a seguir.

\section{A Memória Discursiva}

O sujeito que enuncia o faz de um lugar social, sócio-histórico, a partir de uma posição-sujeito filiada a uma Formação Discursiva, sem que isso se dê no nível consciente. As Formações Discursivas são heterogêneas e relacionam-se de distintos modos. No entanto, em nível consciente, na organização do imaginário, há sempre funcionando o efeito de unidade e homogeneidade do sujeito e dos sentidos. Essa univocidade é desfeita, no momento em que se procede a uma análise mais apurada. As formações discursivas não são homogêneas, elas são transpassadas, entrecortadas por saberes/dizeres produzidos em outras regiões, cujos sentidos são deslocados, dialogam, parafraseiam-se, transformando-se, reelaborando-se, fazendo com que todos os trajetos de uma região a outra pareçam possíveis. Esses saberes/dizeres se constituem por meio do interdiscurso, da memória discursiva, definida por Pêcheux (2010, p. 52) como:

aquilo que, em face de um texto que surge como acontecimento a ler, vem restabelecer os "implícitos" (quer dizer, mais tecnicamente, os pré-construídos, elementos citados e relatados, discursos-transversos, etc), de que sua própria leitura necessita: a condição do legível em relação ao próprio legível. 
Assim, todo dito é um já dito em outro lugar, que atua de forma decisiva no processo de memória/esquecimento, responsável pela ativação de determinadas representações, culturalmente construídas, arquivadas numa memória discursiva, cultural, sócio-histórica e responsáveis pela produção e interpretação dos efeitos de sentidos produzidos nos diversos enunciados. Para Courtine (1981):

A memória concerne à existência histórica do enunciado, no seio de práticas discursivas (...), capaz de dar origem a atos novos, no sentido de que toda a produção discursiva acontece numa conjuntura dada e coloca em movimento formulações anteriores já enunciadas.

É, pois, nessa perspectiva que vamos encontrar o discurso da charge funcionando a partir de uma memória sócio-histórica, redizendo dizeres, ressignificando saberes, construindo subjetividades e fazendo sentidos.

Como a memória, enquanto fato social, é constitutiva do discurso, e todo discurso é deslocado, retomado, opaco, basearemos nosso trabalho no pensamento de Pêcheux (2010, p.56) quando afirma que a memória "é necessariamente um espaço móvel de divisões, de disjunções, de deslocamentos e de retomadas, de conflitos de regularização... Um espaço de desdobramentos, réplicas, polêmicas e contra-discursos". E é nesse espaço que o discurso vai ser construído.

Isto significa que, no discurso, um novo dizer de outros já ditos são passíveis de serem enunciado pelo sujeito, de modo a produzir novos sentidos sempre na relação com a memória discursiva, ou interdiscurso, mesmo que seja uma relação de conflito, deslocamento, diferença, ruptura.

Dessa forma, a memória discursiva é então reconstruída num novo discurso, fazendo com que todo e qualquer discurso, uma vez produzido, torne-se objeto de retomada. Trata-se de um acontecimento único, um fato definido num determinado tempo e num determinado espaço, mas que permite, neste novo dito, a representação de um já dito anteriormente. E é aí, nesta concretização discursiva, que a memória se evidencia.

Esta evidência do passado memorizado vai estar presente no discurso da charge a partir de reformulações que vão readaptá-lo ao novo acontecimento. Embora este parta de um determinado já-dito que está na base do dizível; e assim, haverá um deslocamento do seu uso, possibilitando uma nova contextualização do já dito, um novo 
modo como o sujeito significa em uma situação dada, tornando a possibilidade do sentido vir a ser outro.

O que pretendemos, no decorrer deste trabalho, é mostrar a forma como discursos presentes na memória discursiva de uma formação social brasileira, são retomados e re-significados na charge; analisando nesses discursos, como esta memória discursiva se apresenta e como é renovada em seu sentido.

\section{A imagem, operadora de memória}

Refletir sobre a imagem nos faz remeter sobre a materialidade. "Materialidade significante, modo de textualização imagética, condensada em sentidos" (LAGAZZI, 2010). Pensamos, conforme a autora que o discurso se dá na relação entre a materialidade significante e a história. Desse modo, reiteramos que a imagem é discurso e, portanto, seu processo de significação é também efeito de um trabalho simbólico sobre a cadeia significante, na história, ou seja, a imagem é uma materialidade como outro discurso e, portanto, seu modo significante também formula sentido.

Ao afirmar que todo processo de produção de sentidos tem uma materialidade que lhe é própria, Orlandi (1995, p. 35) afirma que "a significância não se estabelece na indiferença dos materiais que se constituem, ao contrário, é na prática material significante que os sentidos se atualizam, ganham corpo, significando particularmente." Sendo assim, os processos de produção de sentidos têm um modo específico de significar, que estará de acordo com a materialidade significante que lhes constitui.

Ainda conforme a autora, o sentido tem uma matéria própria, já que precisa de sua especificidade para significar. Ele não significa de qualquer maneira. Entre as determinações - as condições de produção de qualquer discurso - estão a determinação da própria "matéria simbólica: o signo verbal, o traço, a imagem e sua consistência significativa" (idem, 1995 p. 39). Assim, entendemos que as condições de produção não são redutíveis ao verbal, embora sejam intercambiáveis sob certas condições.

Souza (2001) aponta para a possibilidade de entender os elementos visuais como operadores de discurso, condição primeira para se desvincular o tratamento da imagem através da sua correlação com o verbal e de se descartarem os métodos que alinham o verbal pelo não-verbal. Então, entendemos que a imagem não pode ser reduzida a segundo plano para o funcionamento do verbal. Ao contrário, há possibilidades de interpretação dos efeitos de sentidos produzidos pela imagem social e historicamente 
determinada, como também pela imbricação do verbal e do não-verbal. Com afirma Souza,

há um Arquivo, cuja forma de inscrição pressupõe uma memória armazenada e institucionalizada na e pela imagem. Não são discursos apenas os textos verbais e orais; também a cestaria, a cerâmica, a pintura corporal, a dança, o traçado organizador da aldeia, a sonoridade das palavras, da música, são formas de discursividade que, quando analisadas em sua relação com a instituição, favorecem compreender como o trabalho da memória histórica gera a memória discursiva nessas sociedades (SOUZA, 1996 e 1998). É possível verificar, então, que o processo de perpetuação da história é bem mais complexo do que uma simples cadeia de comunicação oral e que a imagem - dentre outras formas de expressão não-verbal - é também discurso. (SOUZA, 2001b, p. 18).

Com esta consideração, tomamos o discurso imagético como um exemplar de discurso dotado de historicidade, com seu caráter de incompletude e atravessado por discursos outros que constituem sua discursividade. Verificamos, então, que no funcionamento das materialidades imagéticas, existem possibilidades diversas de leituras, gestos de interpretação distintos, um olhar multidirecional, uma desestabilização do trabalho de interpretação, possibilitando o múltiplo. Por causa dessa pluralidade, a imagem é um discurso de caráter heterogêneo.

Souza afirma ainda que a imagem também tem na sua constituição estas marcas de heterogeneidade e elenca os operadores discursivos que trabalham na imagem, no não-verbal: a cor, o detalhe, o ângulo, luz, sombra, os quais não só trabalham a textualidade da imagem, como instauram a produção de outros textos não-verbais. (SOUZA, 2001b, p. 17).

A imagem também pode ser entendida como uma produção cultural e, como tal, possui sua eficácia simbólica. Dessa maneira, na Análise do Discurso, segundo Davallon (2010), essa eficácia das imagens está fundamentada em algumas características: uma delas é o fato de a compreensão semântica da imagem independer dos pormenores da compreensão das unidades de sua significação. Assim, teríamos a compreensão de um "sentido global antes de reconhecer a significação dos elementos". Outra seria uma possibilidade considerável de reservar a força: a imagem representa a realidade, mas ela pode também conservar a força das relações sociais (e fará então impressão sobre o espectador) segundo Pêcheux (2010 p.27). 
Pensamos assim a importância de se considerar o sentido como "efeito de um trabalho simbólico sobre a cadeia significante", na história, compreendendo a materialidade como o modo significante pelo qual o sentido se formula. (LAGAZZI, 2010, p. 173).

Do mesmo modo que o discurso (em sua materialidade verbal) é opaco, a imagem na $\mathrm{AD}$ também é opaca e reconhecida como um objeto a ser lido e sujeito às mesmas condições sócio-históricas próprias, constituída por relações interdiscursivas. Então, ela é uma manifestação de uma forma-sujeito do discurso, não podendo ser considerada neutra.

Podemos inclusive pensar que, em termos discursivos, a imagem envolve um processo de formulação e um processo de constituição. Isto é, os traços, formas e cores são igualmente atravessados, constitutivamente, pelo interdiscurso.

Sendo assim, concordamos com Davalon (2010), para quem a imagem funciona como um operador da memória social que, ao retratar a realidade, pode também conservar a força das relações sociais. Além disso, na visão do autor, a imagem determina o lugar do observador e as competências necessárias a sua leitura. $\mathrm{O}$ autor cita também que a imagem, por poder operar de acordo com olhares, apresentaria a capacidade de conferir ao quadro da história a força da lembrança. Ela seria, nesse momento, o registro da relação intersubjetiva e social" (ibidem: 2010, p. 31).

Nessa perspectiva de pensar a imagem, é que também podemos associá-la ao interdiscurso, enfatizando a relação entre imagem e memória social:

O poder da imagem é o de possibilitar o retorno de temas e figuras do passado, colocá-lo insistentemente na atualidade, provocar sua emergência na memória presente. A imagem traz discursos que estão em outros lugares e que voltam sob a forma de remissões, retomadas e de efeitos de paráfrases. Por estarem sujeitas aos diálogos interdiscursivos, elas não são transparentemente legíveis, são atravessadas por falas que vêm do seu exterior - a sua colocação em discurso vem clivada de pegadas de outros discursos. (GREGOLIN, 2000, p. 22).

Percebemos que o interdiscurso aparece, portanto, como elemento extremamente relevante para os efeitos de sentido produzidos por uma imagem. Deste modo, é notável também destacar que a imagem (ou elemento imagético) opera discursos outros, pronunciados indefinidamente em outros lugares, fazendo retornos e retomadas de um discurso já formulado. Assim, para a imagem não há um sentido a priori, nem se pode pensar 
em um estatuto de neutralidade para os elementos visuais. Também tais elementos, como temos destacado, refletem as condições próprias de um sujeito que procura significar/interpretar a si e ao mundo a partir de uma materialidade discursiva imagética ou não-verbal diferente da materialidade escrita ou verbal com a qual estamos familiarizados, mas igualmente sujeita a deslizes e equívocos.

Geralmente, ao relacionar as imagens à linguagem verbal da charge, um novo sentido vai ser produzido a partir de uma nova leitura. Segundo Davallon (ibidem 2010, p.29), a imagem assinala um certo lugar ao espectador (ou melhor: ela regula uma série com a passagem de uma a outra posição de receptor no curso da recepção) e ela pode 'rentabilizar' por si mesma a competência semiótica e social desse espectador.

A imagem pode nos oferecer informações ou representar objetos do mundo, entretanto, mais que isso; ela pode ser uma produção cultural carregada de eficácia simbólica. Ela apresenta a capacidade de conferir ao quadro da história a força da lembrança, em forma de memória. Como diz Pêcheux (2010, p. 28): "aquele que observa uma imagem desenvolve uma atividade de produção de significação; esta não lhe é transmitida ou entregue pronta".

Neste pensamento, observamos que há uma liberdade de interpretação (o que quer dizer que o conteúdo "legível", ou antes "dizível" pode variar conforme as leituras); mas o que faz também - e não se poderia esquecer este ponto - com que a imagem comporte um programa de leitura: ela pode se inscrever em uma problemática da memória social.

\section{Análises}

\section{Charge 01(C01)}

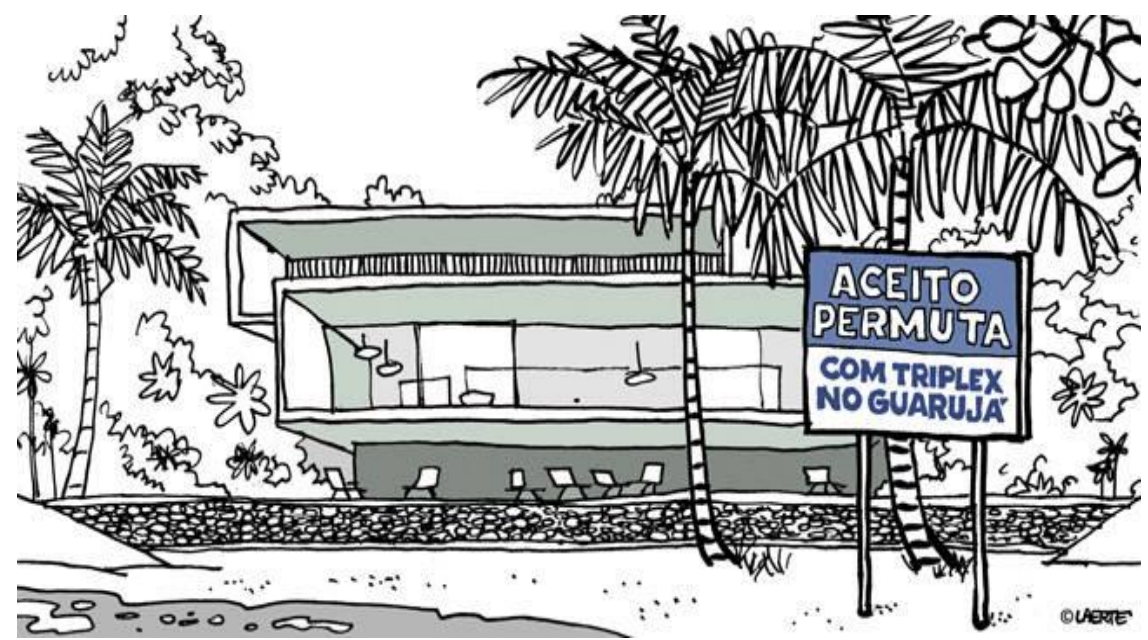

(Charge de Laerte Coutinho) Folha de S. Paulo 16/05/2017. 
Esta charge (C01) foi publicada após investigação pelo Ministério Público Federal, num processo delongado e sem publicidade midiática, da mansão de veraneio dos herdeiros do magnata da Globo, Roberto Marinho, chamada triplex de Paraty, erguida irregularmente, contrariando as leis ambientais do Ministério de Meio Ambiente (MMA).

Das fundações ao teto, o Triplex está localizado em área desmatada de um parque federal. Situa-se também sobre terra pública. Quando a Vara Federal de Angra dos Reis mandou demolir a mansão, em 2010, os advogados dos donos do imóvel recorreram e por sete anos o processo se prolonga no Judiciário. A partir dos acontecimentos citados, alguns jornais publicaram charges, fazendo-lhes referência.

Quando o espectador olha essa charge, é possível que ele a associe à imagem do famoso Tríplex do Guarujá, tantas vezes noticiado na mídia. Porém a imagem da charge não é a do Tríplex mencionado. A retomada se dá pela linguagem verbal "Aceito permuta com Tríplex no Guarujá”. A imagem da charge se refere, como já comentado acima, ao Tríplex dos irmãos Marinho, filhos de Roberto Marinho e herdeiros das organizações Globo, construído, à revelia da lei, em uma área de preservação ambiental na cidade de Paraty, Rio de Janeiro.

Desse modo, alguns elementos do Triplex do Guarujá são reconstruídos no novo discurso, de certa maneira, criticando a nova construção, deslizando para sentidos que questionam principalmente a construção numa área ambientalmente preservada. A mansão ilegal estaria registrada em nome de uma empresa controlada por offshores ${ }^{3}$ do Panamá, uma delas ligada à Mossack \& Fonseca ${ }^{4}$, investigada na Lava Jato.

Percebemos, no texto, uma proposta de permuta entre a mansão ilegal dos Marinho e o, assim designado pela mídia, 'triplex de Lula' no Guarujá — o que retoma à memória dos leitores o "tríplex de Lula", tema usado à exaustão pela Globo como peça de sua campanha contra o ex-presidente. Nesse movimento, identificamos uma formação discursiva de denúncia que estrutura um tratamento tendencioso dos fatos por parte da mídia - ou da 'grande mídia' - em relação a partidos e pessoas da política, no sentido de desgastar apenas a imagem de Lula, Dilma e do PT, naquele momento.

\footnotetext{
3 Offshore é o nome comum dado às contas bancárias e empresas abertas em territórios beneficiários do estatuto de paraíso fiscal, geralmente com o intuito de pagar-se menos impostos do que no país de origem dos seus proprietários ou de ocultar a origem do dinheiro, de crime ou corrupção.

${ }^{4}$ Mossack Fonseca é um escritório de advocacia panamenho fundado em 1977, que abriu diversas contas offshores, que se tornaram centro de um escândalo, conhecido como Panama Papers.
} 
Queremos levar nosso olhar para a Sequência Discursiva (SD): "Aceito permuta". Nela, percebemos o uso da primeira pessoa do singular do modo indicativo que faz com que o sujeito da posição de vendedor seja definido, há um 'eu' que aceita a permuta. Diferentemente de algo mais próprio a uma discursividade do mercado imobiliário em que se encontra com regularidade o uso do verbo na passiva sintética vendem-se casas, ou, enquanto paráfrase dessa SD, aceitam-se permutas - encontramos aqui o verbo em sua forma ativa com o sujeito na primeira pessoa do singular.

Esse movimento na língua pode produzir um efeito de maior proximidade: a relação é direta com o vendedor - ele aceita permuta. Haveria assim, também, um efeito de normalidade, de algo corriqueiro, costumaz. Por outro lado, há ainda outra desestabilização de um funcionamento mais próprio ao discurso do mercado imobiliário na sequência discursiva "com Tríplex no Guarujá": define-se um objeto único da permuta - o tríplex do Guarujá -, diferentemente de sua regularidade em abrir as possibilidades de troca envolvidas em uma possível negociação. Assim há um gesto de "venda", materializado na possibilidade de uma permuta muito bem definida: aquele tríplex de Paraty - juridicamente ilegal - sobre o qual não se comenta na mídia e o tríplex do Guarujá, foco das notícias diárias e estabelecido a priori como ilegal, sem que provas tenham sido contundentemente apresentadas. Nesta permuta definida, fica a pergunta: o que se permuta de fato?

A evidência da ilegalidade que, apesar de sua não comprovação, é dada como evidente? Ou ainda poderíamos pensar que o que se permuta é o problema já constituído (construção em reserva - ou seja, algo juridicamente e circunstancialmente ilegal) por algo que pode vir a ser um problema, mas ainda não comprovado: a suspeição da ilegalidade seria o objeto da permuta? Ou o sujeito vendedor poderia estar desestabilizando esta rede de referentes discursivos e a permuta incidir em sua posição de poder estar acima de qualquer questionamento jurídico, ou seja, o que se permuta é estar acima da lei e, portanto, ser inatingível? O que se permuta é o silenciamento da ilegalidade comprovada na construção do Triplex em Paraty numa reserva de preservação ambiental? Permuta-se o cinismo inscrito na cegueira do problema em função do poder econômico e social que os proprietários do imóvel possuem? Ou o que se permuta são objetos "idênticos" e a sua articulação de equivalência estaria na ordem da ilegalidade? Ambos são fruto de ilegalidade? 
Consistentemente com uma visada discursiva, não tomaremos estas perguntas como disjuntivas. Entendemos que todas estas direções de sentido estão em jogo, ao mesmo tempo, na equivocidade e contradição do funcionamento da charge publicada.

\section{Charge 02(C02)}

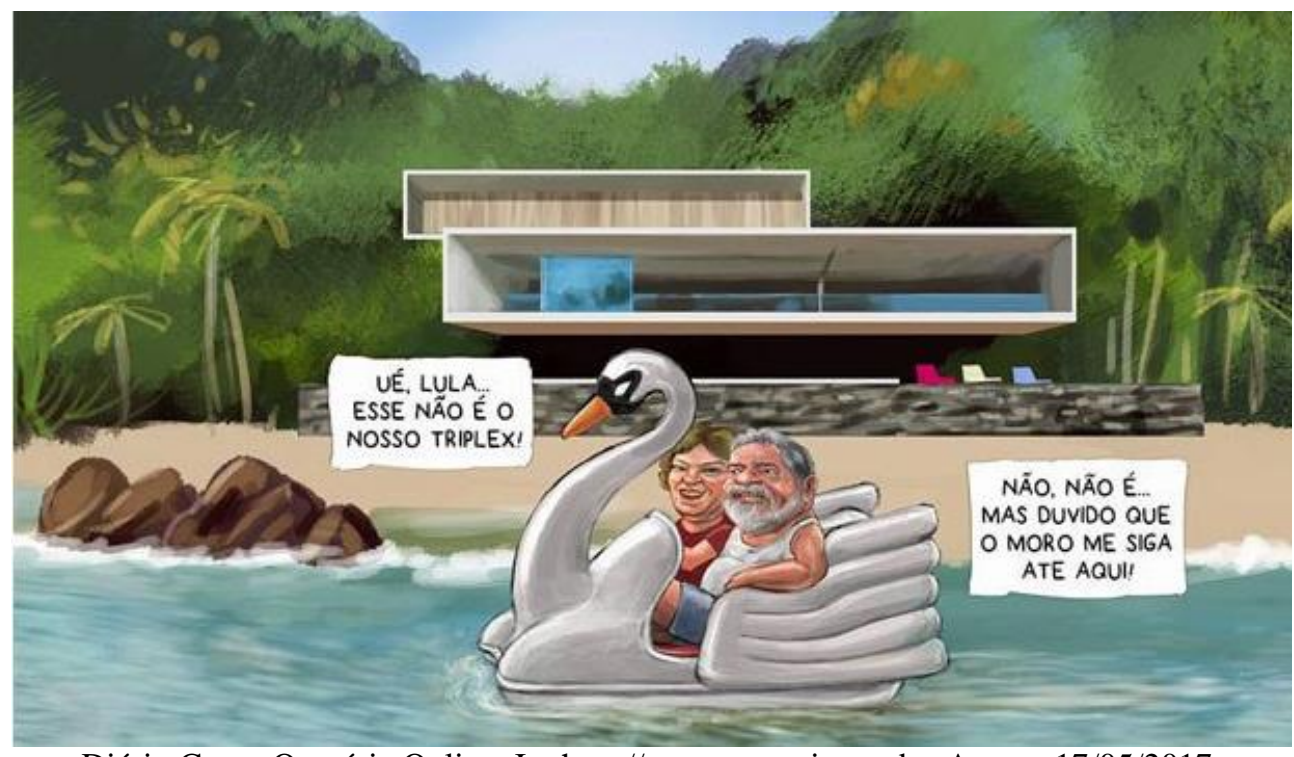

Diário Causa Operária Online. In: http://causaoperaria.org.br. Acesso 17/05/2017.

Esta charge (C02) está sustentada também por um discurso já-dito "o tríplex dos Marinhos", inscrito na memória social, pela circulação de uma imagem prototípica que estabiliza uma denúncia em circulação. Os traços arquitetônicos da mansão construída numa reserva florestal, sendo, portanto, ilegal, estão inscritos neste memorável, configurando alguns dos já-ditos na $\mathrm{C} 02$ e agora retomados, enquanto referência simbólica, através da memória discursiva, ao discurso mais uma vez de denúncia, semelhantemente ao funcionamento do discurso na Charge C01

Retomando Davallon (p.30), "a imagem é antes de tudo um dispositivo que pertence a uma estratégia de comunicação. [...] e um operador de significação". Assim, quando lemos a imagem, a memória discursiva torna-se presente, refletindo um discurso de denúncia. E o que se denuncia? De nosso ponto de vista, o objeto de denúncia se configura em torno da proteção da grande mídia, aquela que esconde fatos, que se repetem corriqueiramente no meio político, judiciário e empresarial do Brasil. A denúncia, aqui, seria então o rompimento de uma "conspiração do silêncio" da grande mídia.

Chamamos a atenção para um deslizamento de sentido da C02 na seguinte SD: “Ué, Lula...Esse não é o nosso tríplex!”. Deslizamento produzido pela relação com as 
imagens em jogo - o referente discursivo do tríplex de Paraty e os traços estereotipados de Lula e de sua esposa Marisa Letícia, chegando de pedalinho na mansão dos Marinho.

Esse deslizamento faz entrar em cena, na materialização do pronome possessivo na primeira pessoa do plural, um outro referente discursivo - o tríplex do Guarujá. Voltaremos a isso mais tarde. No momento, queremos colocar esta articulação entre imagens e essa SD com outra SD: "Não, não é... Mas duvido que o Moro me siga até aqui". Encontramos, nessa articulação, uma ironia que sustenta novamente uma denúncia: a de perseguição política por parte do judiciário, materializada no nome próprio 'Moro' que, ao mesmo tempo, personifica um processo judicial específico e também, por metonímia, simboliza todo o judiciário.

Nessa sequência discursiva, em "duvido que o Moro me siga até aqui" temos então a materialização da perseguição - verbo seguir - que o Juiz Moro faz ao exPresidente e a sua esposa (na época, ainda viva). É ainda na relação entre o verbo “duvidar", a preposição espacial "até" e o advérbio "aqui", que temos a remissão à denúncia de que a lei é 'cega' para quem detém o poder econômico, fazendo referência à morosidade e parcialidade da justiça para julgar a ilegalidade da construção do Tríplex de Paraty.

A denúncia é dupla: há perseguição política para alguns e há isenção para outros. E a ironia se materializa ao pedalar até uma "zona" em que se está protegido pela isenção. Nessa rede discursiva, se faz esta dupla denúncia.

No entanto, como os processos discursivos são contraditórios, queremos voltar para a imagem do pedalinho e o pronome pessoal na primeira pessoa do plural. A imagem de um pedalinho estabelece relação com notícias que fazem parte dos discursos disponíveis sobre o ex-presidente Lula: o de que haveria suspeição sobre a legalidade do dinheiro utilizado na aquisição de um pedalinho que Lula havia presentado sua esposa. Assim, a imagem do pedalinho articulada ao pronome possessivo 'nosso', que permite construir discursivamente a referência ao tríplex do Guarujá, trazem à cena suspeições que estão em jogo contra o ex-presidente Lula. Como dissemos, ao "levar" estes sentidos construídos em uma memória social sobre o ex-presidente Lula defronte ao tríplex de Paraty e enunciar que até ali não seriam seguidos, permite a denúncia: há perseguição e há proteção, porém, os objetos de uma e de outra prática não são coincidentes. No entanto, para se fazer a denúncia, assume-se a posse do tríplex do Guarujá por meio do pronome "nosso" articulado ao significante tríplex. Ou seja, 
contraditoriamente, a denúncia se sustenta no pré-construído da ilegalidade: a forma como se chega à zona de proteção é por meio de um pedalinho e a não coincidência do "tríplex" implica necessariamente que se é proprietário de um outro tríplex - o do Guarujá - objeto de contestação por parte da defesa do ex-presidente.

Ainda poderíamos dizer que há equivocidade na relação com as formas de posse dos dois diferentes Tríplex. Essa diferença poderia retomar, em termos de memória, um discurso colonial patriarcal em contradição a um discurso do mérito pessoal. O primeiro é retomado pela imagem do Tríplex do Paraty, imóvel conquistado à força, através do poder econômico, por homens que sempre o detiveram de maneira hereditária. $\mathrm{O}$ segundo, remete à construção familiar, onde o casal conquista a independência financeira e adquire bens juntos, evidenciada pelo pronome possessivo "nosso"; lembrando que para tanto mantém-se o pressuposto de que exista um tríplex conquistado pelo casal.

Para fechar, queremos fazer referência ainda à memória instalada no pedalinho em relação à forma material pedalada que, por sua vez, instala, pela memória, a expressão "Pedalada fiscal", repetida diversas vezes para justificar o processo de destituição da presidente da República, Dilma Roussef, sucessora de Lula, sua aliada, e do mesmo partido. Essa articulação permite ampliar o objeto de denúncia: não é apenas o ex-presidente Lula que é perseguido politicamente pela instrumentalização do judiciário, mas todo um partido e suas lideranças.

\section{Charge 03(C03)}
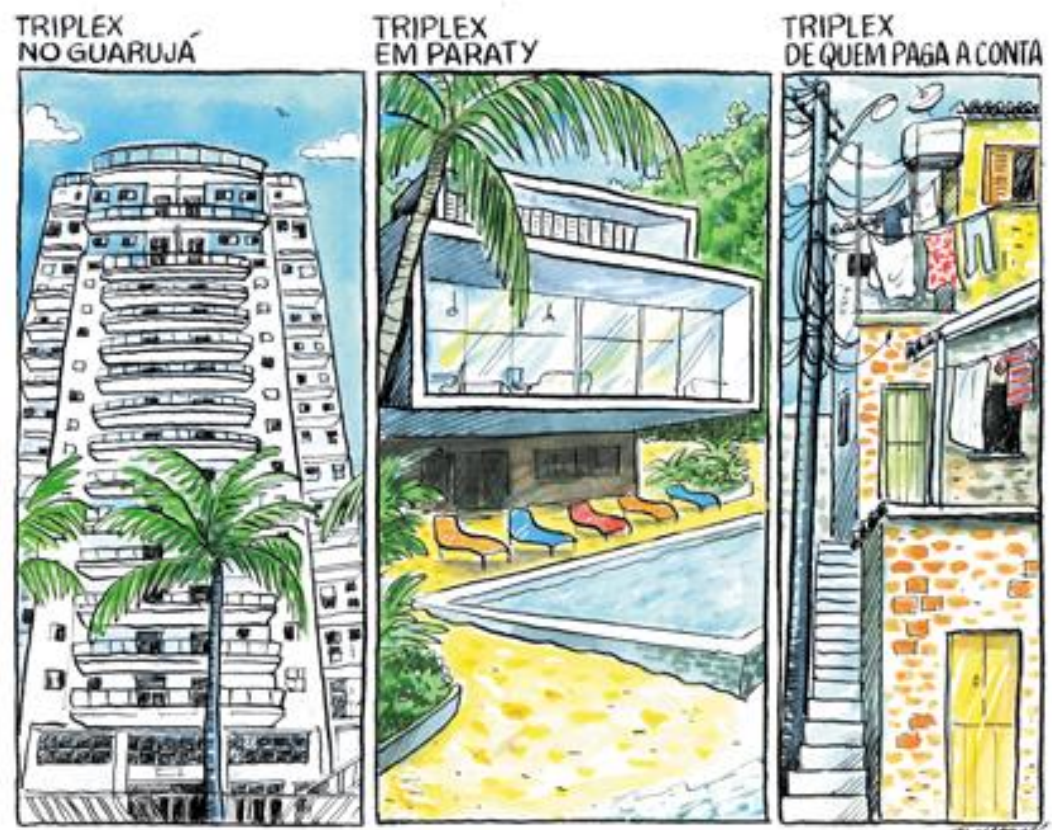

Charge do Clayton. In http://blogdoeliomar.com.br/a-charge-do-clayton-588/ Acesso 17/05/2017. 
$\mathrm{Na} \mathrm{C} 03$, apreendemos a reiteração do mesmo, do já dito, reportando-nos ao interdiscurso do simbólico Triplex. As imagens dos imóveis são retomadas e nos reportam a Lula e aos irmãos Marinho. Ambos são colocados em um mesmo lugar: ilegalidade/corrupção. No entanto, observamos uma equivocidade na retratação do terceiro Triplex, que reporta o já-dito de um imóvel que não possui poder aquisitivo e, de certa forma, constrói seu triplex de maneira também ilegal, efetuada sem licença, em desacordo com a legislação. Desta forma, percebemos um movimento parafrástico de uma discursividade de denúncia nas três imagens.

Na primeira, pressupondo a certeza de quem é a propriedade, em função de a origem do dinheiro que possibilita a aquisição ser considerada ilegal; na segunda, em função da ilegalidade da terra em que foi construída - é pública e se trata de uma reserva; na terceira a denúncia é de outra ordem: a denúncia de ser preciso construir ilegalmente pela ausência de garantias do direito à cidade, do direito à moradia, assim a construção é ilegal, mas a denúncia é sobre as razões que levam à possibilidade deste tipo de construção. E uma das razões é justamente o poder econômico e político de alguns que desviam o dinheiro que deveria estar à disposição de políticas de acesso à moradia digna.

Também queremos observar um rompimento da regularidade das formas verbais que acompanham as imagens. As duas primeiras funcionam como nome próprio dentro de uma legenda; a terceira - "tríplex de quem paga a conta" funciona como uma metonímia dispersa com a qual constrói-se a referência a povo, sociedade e pobre. Há um retorno ao mesmo espaço dizível e, ao mesmo tempo, um discurso polissêmico, porque a materialidade significante deslizou e evidenciou sentidos outros, tais como: quem detém o poder econômico, mesmo na ilegalidade, não sofre as consequências por ter violado as leis; por exemplo, mas quem não detém esse poder, tem suprimido o direito a ter acesso a um Estado de Bem-Estar Comum.

É assim que, a nosso ver, se constrói um discurso de denúncia duplo: há corrupção e quem paga o ônus da corrupção é a população brasileira, retratada no terceiro quadro da charge de maneira bem contrastante. A construção desordenada, malfeita, muitas vezes pela falta de recursos, justamente ironiza as construções faraônicas e o desvio do recurso público ou a isenção do Estado que tem danos terríveis à natureza e aos cofres públicos, nas construções dos tríplex do Guarujá e Paraty. Então, 
o novo discurso demonstra que o usufruto dos ricos corruptos é construído a partir da exploração da população brasileira.

\section{Considerações finais}

Ao analisarmos o interdiscurso e o papel da memória no discurso da charge, visualizamos, através da abordagem teórica, que é no processo da formação discursiva que o discurso assume significados.

Por meio da amostra das análises, foi possível identificar algumas "formas indefinidamente repetíveis" (COURTINE, 1981, p.47) que surgem nas enunciações produzidas a partir de FDs que mantêm entre si uma relação de dependência, de polêmica, de contradição.

Vimos que há uma retomada constante do que é dito em outro lugar, tanto para apoiar quanto para deslocar sentido e que tal retomada será um novo dizer, que não necessariamente pertence ao discurso do Outro.

Segundo Orlandi, o discurso é a linguagem no momento de existência. Nesta dinâmica, destaca-se o interdiscurso, assim como outros conceitos da análise discursiva, como Formação discursiva (FD), condições de produção, memória discursiva, etc; pois o discurso possibilita novas produções de sentidos.

O estudo do discurso da charge revela não só a riqueza de uma materialidade significante, no caso, imagética, mas também, durante o processo de análise, que a incompletude é constitutiva da linguagem, e que todo discurso atualiza sentidos de uma memória que o constitui. Então, cabe ao analista construir o dispositivo de análise, com base no dispositivo teórico, a fim de proceder a um processo analítico. Esse processo precisa considerar a história, a inscrição da política e do político (que decide os sentidos predominantes), o inconsciente e a materialidade significante, uma vez que os sentidos circulam.

Então, atravessada pela historicidade constitutiva do discurso, a charge envolve efeitos de sentido que não decorrem exclusivamente daquilo que se vê, ouve ou lê, mas que derivam de dizeres outros, deslocados e ressignificados no fio interdiscursivo, presentificando fatos e discursos que se deram em outros contextos históricos e que produzem sentidos que vão além da literalidade do dizer.

Neste contexto, o conceito de interdiscurso tem papel privilegiado, propondo formas de descrever os elementos que, em maior ou menor grau, autorizam os sentidos das formações discursivas. Assim, o sujeito é levado a interpretar seguindo algum dos fios condutores que o levam a construir esse ou aquele sentido. Os sentidos são 
constituídos, entre outras coisas, pela capacidade do discurso de articular com maior ou menor proporção a memória discursiva do sujeito. Deste modo, consideramos que "a estruturação do discurso vai constituir a materialidade de uma certa memória social", conforme Pêcheux (2010, p.11)

Acreditamos, numa conclusão provisória, que a proposta do estudo de que a memória que está presente no discurso é sempre esquecida/reconstruída em um novo dito e que a imagem pode ser também operadora dessa memória discursiva, foi observada pelas análises realizadas. Esperamos que o trabalho desenvolvido instigue mais propostas de análise em materialidades significantes diferentes na AD.

\section{Referências}

BARBOSA, P. L. N. O papel da imagem e da memória na escrita jornalística da história do tempo presente. In: Discurso e Mídia: a cultura do espetáculo. São Carlos: Claraluz, 2003.

COURTINE, J. J. Analyse du discours politique. Le discours communiste adressé aux chrétiens. In.: Langages, 62, 1981.

GREGOLIN, M. R. Recitação de mitos: a história nas lentes da mídia. In: GREGOLIN, M.R (org.) Filigranas do discurso: as vozes da história. São Paulo: Cultura Acadêmica, 2000.

LAGAZZI, S. O recorte significante na memória. In: INDURSKY, Freda, FERREIRA, Maria Cristina; MITTMANN, Solange. (Org.). O Discurso na Contemporaneidade. Materialidades e Fronteiras. São Carlos: Claraluz, 2009.

Linha de passe: a materialidade significante em análise. Revista do Laboratório de Estudos Urbanos do Núcleo de Desenvolvimento da Criatividade, n. 16, Volume 2, p.172-183, 2010. Disponível em: http://www.labeurb.unicamp.br/rua/. Acesso em: 28 de setembro de 2017.

ORLANDI, E. Análise de Discurso. Princípios e Procedimentos. Editora Pontes, Campinas, São Paulo, 2005.

A leitura e os leitores possíveis. In : ORLANDI (org.) A Leitura e os Leitores. Campinas: Pontes, 1998.

Interpretação: autoria, leitura e efeitos do trabalho simbólico. Petrópolis -RJ: Vozes, 1998.

Efeitos do verbal sobre o não-verbal. RUA - Revista do Núcleo de Desenvolvimento da Criatividade da Unicamp, n. 1, Campinas: Editora da Unicamp, v.1. n. 1, p. 35-47, 1995.

.Discurso e Leitura. São Paulo: Cortez; Campinas, SP: Unicamp, 2001.

.Discurso de Texto: Formulação e Circulação dos sentidos. Campinas, SP: Pontes, 2001. 
SOUZA, T.C.C. de. Discurso e Oralidade - Um estudo em língua indígena. Tese de Doutorado, UNICAMP, 1994 ( Publicações do Mestrado em Comunicação Imagem e Informação, UFF, Niterói,1999) . Les Formes d'Ecriture et d'Oralité. Conferência realizada na Universidade Paris 13, Paris, fevereiro de 1996.

Discurso e imagem: perspectivas de análise do não-verbal, Conferência no $2^{\circ}$ Colóquio de Analistas del Discurso, Universidad del Plata, Instituto de Linguística da Universidad de Buenos Aires, La Plata e Buenos Aires, 1997b (Publicado em Ciberlegenda 1, Revista Eletrônica do Mestrado em Comunicação, Imagem e Informação, Niterói, UFF, 1998.

RUA - Revista do Núcleo de Desenvolvimento da Criatividade da Unicamp, n. 1, Campinas: Editora da Unicamp, n. 1, v.7. p. 65-94, $2001 \mathrm{a}$.

A análise do não verbal e os usos da imagem nos meios de comunicação. In:

Revista Ciberegenda, $\mathrm{n}^{\circ}$ 6, 2001b. Disponível em: <http://www.uff.br/ciberlegenda/ojs/index.php/revista/article/view/323/204>. Acesso em: 28 de setembro de 2017.

POSSENTI, Sírio. Observações sobre Interdiscurso. Revista Letras, Curitiba, n. 61, especial, p. 253- 269, 2003. Editora UFPR, 2003.

PÊCHEUX, Michel Discurso: Estrutura ou acontecimento. Trad. Eni Puccinelli Orlandi São Paulo: Pontes, 1997.

DAVALLON, Jean. ACHARD, Pierre. DURRAND Jacques. ORLANDI Eni.

Papel de Memória. Trad. José Horta Nunes. Campinas, SP: Pontes, 2010.

RABAÇA, C. A. \& BARBOSA, G. Dicionário de comunicação. Rio de Janeiro: Codecri, 1995.

SIQUERI, M. Formação Discursiva e texto imagético: possibilidades. II Sead. Porto Alegre, 2005. Disponível em <http://www.discurso.ufrgs.br/sead/doc/marcelosiqueri. pdf>. Acesso em 14.jan.2006. 


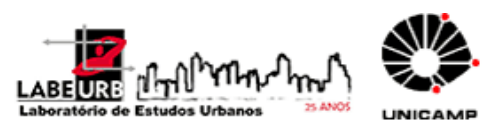

\section{Para citar essa obra:}

CAVALVANTI, Cristiane Renata da Silva; AZEVEDO, Nadia Pereira Golçcalves. O tríplex: a imagem como operadora de memória discursiva em charges. In: RUA [online]. $\mathrm{n}^{\circ}$. 24. Volume 1 - p. 237-253 - e-ISSN 2179-9911 - junho/2018. Consultada no Portal Labeurb - Revista do Laboratório de Estudos Urbanos do Núcleo de Desenvolvimento da Criatividade.

http://www.labeurb.unicamp.br/rua/

Capa: Charge de Laerte Coutinho. Folha de S. Paulo 16/05/2017.

Laboratório de Estudos Urbanos - LABEURB

Núcleo de Desenvolvimento da Criatividade - NUDECRI

Universidade Estadual de Campinas - UNICAMP

http://www.labeurb.unicamp.br/

\section{Endereço:}

LABEURB - LABORATÓRIO DE ESTUDOS URBANOS

UNICAMP/COCEN / NUDECRI

CAIXA POSTAL 6166

Campinas/SP - Brasil

CEP 13083-892

Fone/ Fax: (19) 3521-7900

Contato: http://www.labeurb.unicamp.br/contato 